\title{
ESTÁGIO CURRICULAR SUPERVISIONADO E LABORATÓRIO DE ENSINO DE MATEMÁTICA: AÇÕES FORMATIVAS COMPARTILHADAS COM ESCOLAŞ DE EDUCAÇÃO BÁSICA
}

\author{
Dilza CÔCO \\ Sandra Aparecida Fraga da Silva \\ Instituto Federal do Espírito Santo (IFES), Vitória, Espírito Santo, Brasil
}

\begin{abstract}
Resumo: Este artigo explora a temática: aprendizagens docentes de licenciandos de Matemática no estágio supervisionado. Trata-se de uma investigação que visa a compreender o movimento de ação formativa de licenciandos quando realizam oficinas pedagógicas com estudantes do Ensino Fundamental, em um laboratório de ensino de Matemática. Baseados nos pressupostos da abordagem HistóricoCultural e da Teoria da Atividade, analisamos episódios formativos registrados em relatórios escritos entre 2015 e 2018, que explicitam reflexões, desafios e possibilidades de ensino elaboradas por acadêmicos. As análises indicam que os momentos de planejamento, desenvolvimento e avaliação das oficinas, em uma perspectiva coletiva, contribuem para a constituição de uma nova qualidade de pensamento dos licenciandos sobre a atividade pedagógica.

Palavras-chave: Estágio supervisionado. Matemática. Teoria histórico-cultural. Aprendizagens docentes.
\end{abstract}

\section{INTRODUÇãO}

Historicamente, no Brasil, a área de formação de professores constitui campo amplo de estudos e pesquisas. Ela instiga investigações em diferentes temas, como políticas públicas, currículo, legislações educacionais, materiais didáticos, financiamento e gestão, programas e projetos educacionais, identidade e desenvolvimento profissional, dentre outros. Nesse cenário de possibilidades, identificamos pesquisas a partir de duas grandes dimensões relacionadas à formação inicial ou à formação continuada de professores. Neste artigo, focalizamos discussões e análises sobre dados de investigação vinculados à primeira dimensão, mais especificamente sobre aprendizagens de conhecimentos da docência em ações formativas do estágio curricular supervisionado.

Entendemos que essas ações formativas podem assumir contornos diversos dependendo do curso, da instituição, do projeto pedagógico, das condições objetivas do contexto formativo. Contudo, um elemento se constitui imprescindível e unificador para o estágio curricular supervisionado: a relação eu-outro estabelecida entre licenciandos e os sujeitos de escolas da educação básica (professores, estudantes, outros profissionais) (RODRIGUES, 2014). Nessa perspectiva, concebemos o diálogo entre os vários sujeitos co- 
mo matéria-prima para efetivar encontros comprometidos com o processo de aprendizagem. Desse modo, partimos da premissa da ocorrência e presença de diferentes vozes que ecoam no processo de constituição de aprendizagens docentes dos acadêmicos e, portanto, do desenvolvimento de consciências. Nesse sentido, podemos fazer alusão ao conceito de polifonia de Bakhtin (2005), que realça a importância da compreensão das diferentes vozes que integram os enunciados. Vozes equipotentes ou plenivalentes, percebidas como plenas de valor e com potencial para produzir uma outra qualidade de pensamento dos futuros professores sobre demandas e aspectos constituintes do trabalho pedagógico.

Assumir o estágio como espaço de diálogo entre sujeitos da instituição de ensino superior e da escola básica implica também o desenvolvimento de práticas compartilhadas de formação. Silva (2018) evidencia que nessa concepção de estágio curricular supervisionado é possível organizar situações formativas para que os acadêmicos possam coletivamente pensar, refletir, discutir, elaborar, rever, avaliar e reelaborar proposições e compreensões relacionadas ao trabalho pedagógico. No caso desta pesquisa, estamos tratando de dados sobre o trabalho pedagógico produzido de modo compartilhado, articulando vozes de licenciandos, professores formadores, professores das escolas de educação básica e estudantes do ensino fundamental. Dados esses referentes às etapas de planejamento, desenvolvimento e avaliação de oficinas pedagógicas de matemática realizadas em um laboratório de ensino da instituição formadora, pertencente ao Instituto Federal de Educação, Ciência e Tecnologia do Espírito Santo (Ifes), campus Vitória.

Compreendemos que essas oficinas pedagógicas, desenvolvidas no contexto do estágio curricular supervisionado, colaboram de modo imediato para o desenvolvimento dos sujeitos participantes, mas também produz outros efeitos. Em termos imediatos, inferimos que a oferta das oficinas estimula a aprendizagem de conhecimentos inerentes à atividade de ensino dos licenciandos, assim como propicia condições especiais aos estudantes das escolas públicas atendidas para estudos de conceitos matemáticos. Em relação a outras repercussões, entendemos as oficinas pedagógicas como iniciativas que consolidam o estreitamento de relações entre a instituição formadora e as escolas parceiras de estágio. Além disso, permitem marcar o caráter público da instituição, pois o acolhimento de estudantes do ensino fundamental no espaço do Laboratório de Ensino de Matemática (LEM) possibilita a abertura para a comunidade escolar conhecer melhor as diferentes possibilidades educativas que a instituição oferece, como cursos de ensino médio, profissionalizantes, graduação, especializações e mestrados, além de cursos de extensão.

Com o objetivo de evidenciar os efeitos das oficinas pedagógicas no movimento de aprendizagem de conhecimentos envolvidos no trabalho docente pelos futuros professores, organizamos este artigo em cinco partes, incluindo esta introdução e as considerações finais. Na segunda seção, contextualizamos o modo de organização do estágio curricular do curso analisado e suas vinculações com o LEM. Na terceira, explicitamos as bases teóricas e metodológicas que privilegiamos na pesquisa, para, em seguida, na seção quatro, apresentar um conjunto de dados produzidos em oficinas pedagógicas. Esperamos que as reflexões tecidas neste artigo possam contribuir para a- 
CÔCO, D.; SILVA, S. A. F. da

densar o debate sobre modos de organização do estágio curricular supervisionado na formação inicial de professores, de modo singular, na área de matemática.

\section{ESTÁGIO CURRICULAR SUPERVISIONADO E LABORATÓRIO DE ENSINO DE MATEMÁTICA}

Como sinalizamos, a origem deste artigo está fundamentada em ações de estágio curricular supervisionado desenvolvidas no curso de licenciatura em Matemática do Ifes, campus Vitória. Realçamos que esse curso foi criado em 2008, com base na institucionalização da Lei 11.892, que reconfigurou as atribuições da rede federal de Institutos, inserindo a formação de professores para educação básica como uma das prioridades de atuação. Em 2018, o curso completou dez anos de existência e, nesse período, diversas ações formativas foram desenvolvidas em articulação com escolas de educação básica; dentre elas, ações relacionadas ao estágio curricular supervisionado, ao Programa Institucional de Bolsas de Iniciação à Docência (Pibid) e ao Programa de Residência Pedagógica do governo federal.

Sobre o estágio curricular supervisionado, ressaltamos que esse componente do curso está subdividido em duas etapas, ensino fundamental e ensino médio. Para o ensino fundamental, as ações formativas são ofertadas no $5^{\circ}$ e $6^{\circ}$ períodos do curso, denominadas de Estágio I e lli; já para o ensino médio, no $7^{\circ}$ e $8^{\circ}$ períodos, denominadas de Estágio III e IV. Todos eles contemplam interlocuções com experiências de ensino em escolas regulares da rede pública e das modalidades de Educação de Jovens e Adultos, Educação Profissional e Educação Especial.

Desde o ano de 2011, as autoras deste texto atuam como docentes nas disciplinas de Estágio I e II. Inicialmente, a configuração das ações formativas adotava o modelo clássico de estágio supervisionado, com as etapas de observação, coparticipação e regência em aulas de matemática em escolas públicas. A partir de 2015, instauramos nova dinâmica para o estágio, implementando ações no LEM do instituto, relacionadas à oferta de oficinas pedagógicas a alunos das escolas parceiras do estágio. A realização dessas oficinas sucede um período de interações regulares dos licenciandos com professores de matemática e estudantes do ensino fundamental nas escolas. Assim, ocorre a inserção do licenciando no ambiente escolar para conhecer melhor os sujeitos, as condições objetivas da realidade escolar e as demandas e necessidades do trabalho pedagógico. A partir desse processo inicial de interlocução, são organizadas e viabilizadas parcerias com as escolas para reunir condições (agenda, materiais, lanche, transporte, definição de conceitos a serem abordados etc.) para realização das oficinas.

Destacamos que o LEM do Ifes se configura como um espaço especializado que oferece recursos didáticos (materiais manipulativos, jogos, computadores com acesso à internet, lousa digital, Datashow etc.) e mobiliários (mesas coletivas, cadeiras, armários...) que favorecem ações de ensino e aprendizagem de matemática. Esse espaço foi criado no ano de 1989, com o objetivo inicial de atender a demandas pedagógicas internas da instituição, mas, ao longo do tempo, foi se reestruturando e passou a ser utilizado para atividades de pesquisa, ensino e extensão, especialmente a partir do momento da criação do curso de licenciatura em Matemática (2008) e do mestrado profissional em Educação em Ciências e Matemática (2011). 
Notamos que a oferta das oficinas pedagógicas como ações do estágio curricular supervisionado possibilita condições para que os licenciandos assumam a organização do ensino em uma totalidade (planejamento, desenvolvimento e avaliação). Esse movimento permite que, "ao fazê-lo [organização do ensino], suas ações vão adquirindo novas qualidades, determinando um movimento em sua formação que lhe confere cada vez mais capacidade para lidar com seu objeto, que é a atividade pedagógica" (LOPES, 2009, p. 75).

Nessa perspectiva formativa, realizamos uma série de oficinas, identificadas por ano de realização, licenciandos responsáveis e temáticas abordadas, conforme dados do Quadro 1. Cabe esclarecer que para a identificação dos licenciandos foram atribuídos nomes fictícios com o objetivo de preservar a identidade dos envolvidos.

Quadro 1 - Oficinas pedagógicas no estágio curricular supervisionado no LEM

\begin{tabular}{|c|c|c|}
\hline Ano & $\begin{array}{c}\text { Licenciandos } \\
\text { envolvidos }\end{array}$ & Tema (turma) \\
\hline \multirow{4}{*}{2015} & Soraia & Razões trigonométricas ( $8^{\text {a }}$ série $)$ \\
\hline & Kauã & $\begin{array}{l}\text { Razões trigonométricas do triângulo retângulo ( } 9^{\circ} \\
\text { ano) }\end{array}$ \\
\hline & Dina & Operações com números inteiros ( $6^{\mathrm{a}}$ série $)$ \\
\hline & Maristela e Stael & Fatoração e mínimo múltiplo comum $\left(6^{\circ}\right.$ ano $)$ \\
\hline \multirow{2}{*}{2016} & Jonas, Udson e Marcos & Área de figuras planas (Turmas de EJA) \\
\hline & Alessandro & Polígonos ( $8^{\circ}$ ano $)$ \\
\hline \multirow{5}{*}{2017} & Aldo, Max e Assis & Escala e proporção $\left(6^{\circ}\right.$ ano $)$ \\
\hline & Marta e Alan & Área e perímetro em figuras planas (Turma de EJA) \\
\hline & Fátima e Robson & Área e perímetro em figuras planas (Turma de EJA) \\
\hline & Geraldo e Elen & Produtos notáveis $\left(8^{\circ}\right.$ ano $)$ \\
\hline & Fernanda e Celso & Polígonos $\left(8^{\circ}\right.$ ano $)$ \\
\hline 2018 & Yolanda e Alex & Operações com números inteiros $\left(6^{\circ}\right.$ ano $)$ \\
\hline
\end{tabular}

Fonte: Dados da pesquisa.

Salientamos que essas oficinas no LEM foram realizadas a partir da disponibilidade das escolas e demandas pedagógicas específicas quanto ao conteúdo abordado. Entretanto, é importante explicitar que não foi possível atender a todas as escolas parceiras do estágio em razão de algumas situações desafiantes para a gestão das escolas. Um aspecto bastante recorrente diz respeito à distância de algumas escolas em relação à localização do Ifes, sendo essa condição agravada pelo restrito fornecimento de transporte pelos sistemas públicos de ensino para as escolas. Nesses casos, os licenciandos planejavam as ações de ensino, conforme indicações de conteúdos especificados pelos professores regentes, e as realizavam no contexto escolar. Em muitas dessas situações foram utilizados recursos e materiais didáticos do LEM para favorecer a abordagem do conteúdo matemático, reafirmando a importância da existência do laboratório e do seu acervo para o desenvolvimento das ações formativas do estágio curricular supervisionado. 
CÔCO, D.; SILVA, S. A. F. da

\section{APORTE TEÓRICO-METODOLÓGICO}

Para compreender o processo de aprendizagem de conhecimentos da docência em ações de estágio curricular supervisionado, ancoramo-nos em fundamentos da perspectiva Histórico-cultural, sistematizada por Vigotski e colaboradores, e da Teoria da Atividade desenvolvida por Leontiev. Nesse referencial, alguns conceitos são essenciais, dentre eles o de apropriação. Segundo Leontiev (1978), o processo de apropriação do que foi criado pela humanidade ocorre durante as relações reais do sujeito com o mundo e são influenciadas por questões históricas, sociais e de condições de vida. Entretanto, "quanto mais progride a humanidade, mais rica é a prática sócio-histórica acumulada por ela, mais cresce o papel específico da educação e mais complexa é a sua tarefa" (LEONTIEV, 1978, p. 273). Ainda que ao longo do tempo essa tarefa específica tenha sido organizada de diferentes maneiras, havia sempre uma necessidade de formação para realizá-la.

Nesse contexto, a escola é entendida como "o espaço criado pela sociedade humana para os processos de socialização dos saberes" (MOURA, 2000, p. 43). Para essa socialização, é necessário que as ações de formação ajudem o professor no seu fazer, no seu trabalho, que é o ensino que se efetua a partir da atividade pedagógica. Esta está ligada aos sujeitos que dela participam, à atividade de ensino do professor e à atividade de estudo do aluno. Segundo Moura (2000), compreender a atividade de ensino nessa perspectiva nos ajuda a entendê-la como unidade de formação entre os sujeitos envolvidos, para que o objetivo de ensinar e de obter condições de aprendizagem seja organizado de maneira adequada e intencional. Desse modo, a ação de ensino impacta tanto o professor como o aluno e indica uma "mudança nessa realidade por meio de uma ferramenta simbólica. Isso implica a definição de objetivos, por quem ensina [...] é uma necessidade de fazer com que determinados sujeitos se apropriem de certos conhecimentos" (MOURA, 2000, p. 31). Esse processo demanda troca de significado entre diferentes sujeitos participantes do processo.

Moura (2000, p. 32) destaca que "as ações para a formação inicial do professor, que se deve convencer do valor de um conteúdo escolar, são diferentes da ação a ser desenvolvida para convencer um aluno da importância da sua aprendizagem". Na formação, precisamos mostrar a importância de ensinar determinado conteúdo; já no ensino, precisamos ajudar o aluno a compreender o significado social do conteúdo trabalhado. Esses motivos se misturam, mas precisam ser explorados de maneira diferente. Além disso, o professor precisa pensar em ferramentas simbólicas que the ajudarão a modificar a realidade a partir de sua atividade pedagógica. No estágio, notamos que os licenciandos estão trabalhando nos dois polos, pois estão realizando atividade de estudo e precisam pensar em atividades de ensino, o que modifica a relação desse sujeito com o objeto que ensina. Compreendemos, assim, que a atividade

[...] é do sujeito, é problema, desencadeia uma busca de solução, permite um avanço do conhecimento desse sujeito por meio do processo de análise e síntese e lhe permite desenvolver a capacidade de lidar com outros conhecimentos a partir dos conhecimentos que vai adquirindo à medida que desenvolve a sua capacidade de resolver problemas. A atividade é desse modo um elemento de formação do aluno e do professor. Um se modifica ao trocar signifi- 
cados; o outro, a partir da criação de novas ferramentas para favorecer a aprendizagem, revê objetivos educacionais, conteúdos e estratégias de ensino num processo contínuo de avaliação de seu trabalho (MOURA, 2000, p. 35).

Entendemos, também, que esse modo de conceber a atividade de ensino precisa estar presente em discussões teórico-práticas com licenciandos e que "o contexto do estágio pode caracterizar-se como um momento especial para a regulação da atividade profissional dos licenciandos" (DIAS; SOUZA, 2017, p. 196). Eles precisam se apropriar de uma nova maneira de olhar a escola, o conhecimento e o trabalho do professor. Precisam entender que a ação do professor é ampla e requer um novo olhar para o fazer docente. Precisam de planejamento, reflexão, compreensão de como os alunos aprendem, de ferramentas e materiais que possam auxiliar nesta compreensão e precisam avaliar continuamente suas ações. Nesse sentido, Dias e Souza (2017, p. 190) apontam que "o momento do estágio tende a propiciar uma manifestação de relações novas entre os conteúdos vistos nas disciplinas de formação e a atual realidade escolar". Essas autoras ainda destacam que, "[...] nessa fase, o licenciando percebe a necessidade de lidar com uma complexidade de elementos inerentes aos chamados conteúdos específicos e pedagógicos" (DIAS; SOUZA, 2017, p. 190). Essa complexidade precisa se estabelecer na dialética e "evidencia a necessidade de explicitar por que o estágio é teoria e prática e não teoria ou prática e, muito menos, a prática da teoria" (SILVA; CEDRO, 2015, p. 4).

As ações formativas do estágio curricular supervisionado nesse tipo de abordagem que envolve questões teórico-práticas se articulam a proposições de Moura (1999, p. 8-9), quando afirma que o licenciando

[...] diante de situações em que a combinação teoria-prática possa ser vivenciada, de forma a desenvolver, neste professor, a construção de modos de ação que lhes permitam desenvolver o gosto pelo conhecimento que possa iluminar a sua prática.

Para explorar essas relações dialéticas entre teoria e prática e compreender o movimento de aprendizagem da docência pelos futuros professores, organizamos a exposição de dados deste artigo a partir do conceito de episódios formativos. De acordo com Moura (2000), a noção de episódio refere-se a momentos ou informações que revelam processos de mudanças que explicitam uma outra qualidade para aprendizagens dos sujeitos. Esses episódios são constituídos por cenas que colocam à vista o processo de reflexão e de mudança no modo de compreender os elementos da atividade pedagógica. Silva (2018) adensa essas discussões formulando o conceito de flashes. Para a autora, os flashes são manifestações verbais que expressam indícios do processo de significação dos sujeitos. Embora esses indícios sejam de ordem singular, Silva (2018) realça que não são manifestações isoladas, independentes, individuais. Estão em conexão com as interações coletivas, efetivadas por meio das diferentes formas de diálogo que ocorrem entre os sujeitos participantes das ações de estágio supervisionado. 
CÔCO, D.; SILVA, S. A. F. da

Considerando esses apontamentos de base, buscamos identificar nexos entre as atividades formativas desenvolvidas no estágio e o processo de constituição de uma nova qualidade dos conhecimentos docentes dos futuros professores. A apreensão desses nexos é buscada em enunciados elaborados por licenciandos e registrados em relatórios escritos que narram as experiências formativas realizadas nas oficinas pedagógicas no LEM. Destacamos que, para este texto, realizamos um recorte de dados, pois o acervo da pesquisa é composto por um conjunto maior de relatórios que explicitam aprendizagens docentes em diferentes espaços educativos. Como nosso foco está nas aprendizagens docentes desenvolvidas no espaço do LEM, organizamos as análises em três episódios, com cenas relacionadas às etapas de planejamento, desenvolvimento e avaliação das oficinas pedagógicas realizadas nesse ambiente.

\section{ATIVIDADE DE ESTÁGIO CURRICULAR SUPERVISIONADO, LABORATÓRIO DE ENSINO DE MATEMÁTICA E APRENDIZAGEM DA DOCÊNCIA}

Nossas análises partem da premissa de que a atividade de ensino no estágio supervisionado constitui o centro nuclear do desenvolvimento dos sujeitos em formação. O professor, ou futuro professor, ao organizar o ensino de forma intencional e sistematizada, com o objetivo de gerar situações desencadeadoras de aprendizagem, sente necessidades. Essas necessidades podem ser pensadas em termos do domínio dos conteúdos que serão ensinados, escolha dos recursos didáticos para abordá-los, observação das características dos estudantes e das condições objetivas da ação didática. Além disso, também precisa elaborar estratégias para avaliar o processo de apropriação dos conhecimentos, ou seja, sua atividade principal (trabalho) está permeada de aspectos que o colocam em ação, em movimento físico e psíquico. Essas proposições apresentam conexões com o que Moretti e Moura (2011, p. 443) afirmam:

\footnotetext{
O professor, movido pela sua necessidade, encontra-se em atividade de ensino antes, durante e depois de seu encontro com os alunos na sala de aula. Oscilando entre momentos de reflexão teórica e ação prática, e complementando-os simultaneamente, o professor vai se constituindo como profissional por meio de seu trabalho docente, ou seja, da práxis pedagógica.
}

Desse modo, a atividade de ensino, em seus diferentes momentos, contribui e provoca o desenvolvimento do professor. Entretanto, não estamos nos referindo a qualquer ensino, mas a atividades que promovem o desenvolvimento autônomo dos estudantes e possibilitam a apropriação dos conceitos científicos. Para evidenciar tais premissas, iniciamos nossas análises com dados que indicam uma nova qualidade de pensamento dos licenciandos quando eles se envolvem na ação de planejar a atividade pedagógica. Ressaltamos que utilizamos os enunciados dos alunos sem alterar sua estrutura ou texto. 


\section{Episódio 1: Planejamento de ensino e aprendizagem docente}

Soraia (2015) - Durante o estágio vi o quanto é importante planejar as aulas, pois o planejamento nos leva a estudar os conteúdos, a aprimorar nossos conhecimentos e nos ajuda a verificar e atingir nossos objetivos para um melhor ensino. O planejamento das atividades que fiz foram baseadas em minha experiência no Pibid, das aulas de Orte [disciplina do curso de licenciatura] e dos textos lidos em estágio II, fato esse que me ajudou muito. Através dos textos lidos consegui planejar as atividades e determinar quais objetivos queria alcançar com as tarefas e como poderia através delas ajudar no ensino [conteúdo de semelhança de triângulos] daqueles alunos. Kauã (2015) - [A oficina] foi realizada em uma turma de $9^{\circ}$ ano e o tema escolhido foi razões trigonométricas no triângulo retângulo. A escolha da turma foi devido a um fato bem pessoal: quanto mais novos os alunos, maior a minha dificuldade de me relacionar. E mais, sinto que quanto mais 'simples' possa parecer o assunto, mais difícil de ensinar ele é. Para planejar tomei como referência dois materiais: o livro Matemática hoje é feita assim de José Antônio Bigode e uma proposta de oficina de um professor da licenciatura. Essa última eu já havia participado anteriormente e até ministrado em uma turma do segundo ano do ensino médio. [...] Planejar a oficina foi extremamente difícil. Foi necessária muita ajuda da professora de estágio para esboçar alguma coisa. Não sabia nem distinguir objetivos gerais dos específicos. Apesar de conseguir apresentar alguma melhora no planejamento, ainda foi difícil seguir o 'plano perfeito' elaborado em minha cabeça e alcançar os objetivos.

Dina (2015) - [Inicialmente] ficou resolvido com a professora regente que a oficina seria sobre equações. [...] procurei algumas bibliografias, conversei com colegas que tinham experiência para me orientar e aos poucos foi fluindo. O problema é que faltando menos de dez dias para a regência a professora da turma pediu que eu mudasse o tema da aula, [...] então passou para operações fundamentais com números inteiros [...]. Voltei a pesquisar, internet, livros, colegas de sala, todos me auxiliaram um pouco, mas o que mais chamou minha atenção foi um plano de aula de bolsista do Pibid que apresentava um jogo para ensinar operações com números inteiros. Planejar uma aula não é nada fácil, surgiram várias dúvidas principalmente na hora de planejar a lista de exercícios, tive medo de ser exigente demais e os alunos não participarem da aula ou subestimar e tornar a aula tediosa. Por fim o plano de aula ficou pronto, ou pelo menos, eu achei que estivesse. Procurei a professora orientadora do estágio para que ela avaliasse e me orientasse, ficamos em torno de duas horas analisando o plano e ela me dizendo o que eu poderia fazer para melhorá-lo. Ela falou que poderia usar, além do jogo do bingo, a reta numérica para que os alunos pudessem entender melhor o conceito de números inteiros e também uma tabela de temperatura envolvendo números positivos e negativos.

Marcos (2016) - Pensei em propor algo diferente do que o professor fazia, mas ao final não o fizemos por medo dos alunos não aceitarem uma proposta diferente do que estavam acostumados e também por insegurança. [...] a insegurança frente aos alunos atrapalha um pouco, além disso pensar em formas de explicar determinados problemas também foi desafiador.

Elen (2017) - Para fazer o planejamento consultei vídeos educativos, artigos acadêmicos e livros didáticos, mas principalmente as sugestões do professor [da disciplina de estágio] foram as que mais me orientaram na abordagem dos conteúdos da oficina. Durante a preparação a dificuldade que eu tive foi pensar como explicar de forma mais simples o tema escolhido, já que, para mim, ensinar produtos notáveis mediante uma abordagem geométrica era algo novo. Outra dificuldade e preocupação que eu enfrentei ao preparar a oficina foi em pensar ou prever que situações ou perguntas que poderiam aparecer.

Fernanda (2017) - O professor regente sugeriu que preparássemos uma oficina sobre construção de polígonos com régua e compasso para uma turma de $8^{\circ}$ ano. Minha preocupação inicial era saber se eu conseguiria fazer os alunos entenderem a proposta da tarefa. Para não passar vergonha, eu levei a tarefa para os meus alunos [onde fazia estágio em uma escola privada] e pra minha surpresa foi algo bem tranquilo, pude captar qual seria o melhor caminho para direcionar os outros alunos [da oficina] durante as construções. [...] [O meu colega de estágio] ficou responsável por conferir os materiais disponíveis no LEM e aparentemente estava tudo pronto e certo.

Ingrid (2018) - Usamos como base para a atividade o Jogo "Desce e Sobe" e trabalhamos alguns conceitos com base nos livros didáticos. A princípio a primeira barreira foi esquematizar o plano de aula. Fizemos um plano bastante simples, onde basicamente colocamos alguns passos importantes e segmentamos o nosso tempo.

Fonte: Dados da pesquisa.

Os enunciados que compõem os extratos do episódio 1 indicam que a etapa de planejamento das oficinas desenvolvidas no LEM pode ser considerada um momento propício para gerar tensões criativas (MOURA; SFORNI; LOPES, 2017). Os dados sinalizam 
que os licenciandos recuperam referências em experiências significativas vivenciadas no Pibid, em outras disciplinas do curso e com o próprio acervo do conteúdo do estágio supervisionado, como afirmou Soraia. Além disso, evidenciam necessidades quanto à retomada de conteúdos matemáticos em uma perspectiva pedagógica e mostram que os licenciandos estão interessados em estudar e entender o conteúdo para encontrar formas de ensinar melhor. Os extratos apontam, ainda, que alguns conteúdos que inicialmente pareciam ser simples para os licenciandos e de fácil abordagem, na preparação das oficinas se evidenciaram com um grau de complexidade que ainda não tinham sentido, como comenta Kauã.

Para buscar minimizar esses desafios, os acadêmicos recorrem a diferentes fontes, como livros didáticos, artigos científicos, bem como dialogam com professores da licenciatura e outros colegas do curso para obter informações e trocar ideias que possam auxiliar na organização didática e nos modos de ação, como verificamos nos enunciados de Dina e Ingrid. Nota-se que a etapa do planejamento mobiliza relações coletivas e promove o diálogo entre os sujeitos da formação (licenciandos, professores regentes, alunos, professores de estágio, demais professores do curso).

Nessa perspectiva, o planejamento do ensino assume características compartilhadas (SILVA; CEDRO, 2015). Quando os licenciandos mencionam preocupações com a compreensão dos alunos, com o nível de complexidade das tarefas, com possíveis questionamentos e dúvidas dos educandos e com estratégias adotadas para qualificar suas futuras ações de ensino, explicitam que na relação com o outro é que constituímos condições concretas para nosso desenvolvimento, nesse caso para o trabalho docente. $O$ outro é imprescindível em nossa singularidade, como pontuado pelos enunciados da licencianda Fernanda, que experimentou previamente as tarefas com outros alunos para sentir segurança ou, nas palavras dela, "para não passar vergonha".

A parceria com os professores do estágio também se destaca no conjunto dos dados, pois os licenciandos, em especial Dina, Kauã e Elen, estabelecem relações de confiança para apresentarem suas dúvidas, ansiedades e proposições de planejamento. Na busca por apoio para a elaboração de suas propostas, instauram-se relações marcadas pela liberdade de expressão, diálogo, respeito mútuo e solidariedade, possibilitando movimentos reflexivos e a constituição de uma nova consciência sobre demandas do trabalho pedagógico em termos da abordagem de conteúdos específicos e pedagógicos. Percebemos que o conjunto discursivo que delineia o episódio 1 pontua conexões com o conceito de auditório social, desenvolvido por Bakhtin (2003), pois os enunciados individuais não podem ser compreendidos como elaborações independentes, à revelia do outro. Pelo contrário, estão permeados de antecipações ou avaliações que entendemos que o outro pode nos fornecer. Assim, as ansiedades, expectativas e preocupações explicitadas pelos acadêmicos durante o processo de planejamento são elaborações singulares que revelam relações dialógicas e apontam para o processo de mudança dos sujeitos da condição de alunos a professores.

Essas relações se intensificam em um segundo momento, na etapa de desenvolvimento das oficinas. A efetivação do encontro dos sujeitos da universidade com os da escola básica no espaço do LEM possibilita instaurar condições para o adensamento de outras reflexões sobre desafios e demandas da atividade pedagógica, conforme podemos apreender do conteúdo dos extratos do episódio 2 . 
Episódio 2 - Desenvolvimento das oficinas pedagógicas e aprendizagem docente

Soraia (2015) - Iniciamos a oficina no LEM perguntando se os alunos conheciam o transferidor e se já sabiam como utilizá-los. Alguns disseram que sim, mas na tarefa mostraram que não sabiam. [...] peguei um triângulo de cartolina e [...] mostrei aos alunos como se media um ângulo utilizando o transferidor. Alguns entenderam e outros mostraram que não haviam entendido. [...] Isso chamou bastante minha atenção, pois a régua é um instrumento de medida muito utilizado desde os anos iniciais. [...] O que parecia ser trivial e óbvio, mostrou-se um grande dificultador. [...] Fui ao quadro e fiz um triângulo retângulo e identifiquei os ângulos e os lados. Ao fazer o triângulo, na ânsia de desenhar e explicar, não notei que havia feito um triângulo retângulo, diferente do que os alunos possuíam, pois os ângulos internos do meu desenho, no quadro, eram de 90, 30 e 60 graus, e os triângulos que eles possuíam eram de 90, 45 e 45 graus. [...] isso levou alguns alunos a não entenderem o que estavam fazendo, devido ao desenho ser diferente do triângulo que eles possuíam. Devo prestar mais atenção no que desenho no quadro, pois induzo meus alunos a errarem e depois não consigo perceber o motivo do que os levou a cometerem o erro. A atividade continuou e encontramos outra dificuldade, que foi trabalhar razões. Eles não sabiam o que era uma razão, expliquei no quadro e fiz um exemplo. Outra observação é que tenho que ter mais cuidado na organização do quadro, notei isso depois que escrevi as razões e fui tirar uma dúvida de uma aluna, que estava sentada no final do laboratório. [Depois observei que] havia colocado informações fora de ordem, isso pode levar o aluno a cometer erros, confundindo-os.

Stael (2015) - Na [oficina] percebi que tem alguns conceitos que para mim são óbvios, e que eu jamais pensava que eles [alunos] iam perguntar. Assim, na hora eu fiquei muito surpreendida com as perguntas, perguntaram o que era propriedade, o que era número par. Tipo assim, são coisas que são tão óbvias, entre aspas, mas que a gente está tão acostumada a falar que é difícil explicar. E eu não sabia explicar o que era. Então eu vi que tem que fazer um estudo antes sobre as dúvidas que eles podem ter para a gente tentar se antecipar.

Marcos (2016) - Não foi possível seguir por completo o planejamento, pois algumas etapas que havia planejado não foram cumpridas. Como exemplo posso citar a resolução dos problemas no quadro pelos alunos e, posteriormente, as discussões sobre essas resoluções com a turma, etapa inviabilizada pela falta de tempo. Uma das maiores dificuldades que percebi é como conseguir dar atenção necessária a todos os alunos na elucidação das dúvidas que vão surgindo.

Elen (2017) - Por estar mais familiarizada com esse conteúdo [áreas de figuras planas] fez com que tivesse mais confiança nas minhas explicações. A segunda parte da oficina se tornou mais difícil de explicar. Talvez porque achei que os alunos conseguiriam seguir o raciocínio do desenvolvimento de cada um dos produtos notáveis abordado inicialmente de forma algébrica e depois exemplificando com números, mas não foi como esperávamos. O professor orientador do estágio sugeriu começar com um exemplo particular e logo generalizar. Tal modificação durante a oficina gerou um bloqueio e insegurança em mim de como explicar. [...] A insegurança tomou conta e não me permitiu desenvolver como na primeira parte da oficina. Por termos que modificar a forma de abordar essa parte, minha impressão é que os alunos não conseguiram assimilar como se obtêm os produtos notáveis a partir de figuras planas, mas acho que eles compreenderam o sentido da oficina, já que por várias vezes foi indicado que o que eles estão estudando pode ser demonstrado geometricamente tal como os antigos matemáticos faziam para a resolução de equações. [...] Na terceira parte os alunos já estavam cansados e não se interessaram em aprender outra forma de resolver produtos notáveis a não ser da forma mais simples e rápida que tinham aprendido em sala de aula, por meio do algoritmo.

Fernanda (2017) - A quantidade de alunos presentes (24) foi uma surpresa, porque não houve aula na escola e eles só levantaram cedo para participar da nossa oficina. Cada aluno recebeu duas folhas de papel sulfite, um compasso, um lápis e um esquadro. As borrachas foram compartilhadas porque não houve quantidade suficiente para todos. Era hora de começar, a gente ensaia em casa e na frente do espelho, volta e conversa com o colega e ainda sim o frio na barriga é grande quando são os alunos e professores na nossa frente. $O$ meu colega, parceiro no estágio, já queria começar falando do compasso, daí lembrei que pelo nervosismo do momento a gente nem havia se apresentado direito, então eu fui e nos apresentei e agradeci a presença de todos. A primeira tarefa era sobre o uso do compasso, muitos alunos não sabiam como manusear e então deixamos eles tentarem fazer circunferências em uma das folhas, aos poucos todos conseguiram fazer e se empolgavam em fazer várias.

Ingrid (2018) - Logo depois expliquei como funcionaria o jogo e me esqueci de uma das regras, a professora me lembrou e eu reformulei a explicação antes dos alunos começarem a jogar. Eles começaram as partidas e fomos acompanhando de mesa em mesa. No meio do processo percebi que um dos tabuleiros continha um erro, ele ia do zero ao -10, o que poderia causar um conflito no que foi ensinado. Então troquei por um tabuleiro extra que tínhamos. Logo depois a professora me apontou outro tabuleiro com o mesmo erro, mas não tínhamos mais tabuleiros sobressalentes, então, a professora nos incentivou a "arrumar" o tabuleiro ali mesmo.

Fonte: Dados da pesquisa. 
CÔCO, D.; SILVA, S. A. F. da

Os dados do episódio 2 narram encontros dos licenciandos com os estudantes, na condição de futuros professores em situações de ensino. Nesses dados, podemos notar enunciados que pontuam desafios, reflexões e aprendizagens dos acadêmicos. Ao experimentar o lugar da docência e objetivar o planejamento idealizado, tiveram oportunidade de analisar potencialidades e lacunas das suas propostas pedagógicas. Nas interações com os estudantes, os acadêmicos constatam a insuficiência dos seus conhecimentos acerca do ensino. O que confirma os indicativos de Dias e Souza (2017) sobre o estágio. Caraça (1951, p. 199) realça que esse processo sinaliza que "para cada exigência nova que aparece, é uma insuficiência antiga que se descobre, é uma barreira que tem de se derrubar".

Assim, inferimos que os licenciandos, ao serem envolvidos em uma situação nova, como a realização das oficinas pedagógicas, tiveram condições para tomar consciência de suas qualidades, mas também das fragilidades das atuações na condição de futuros professores, como bem relata Soraia sobre o seu modo de registro na lousa, Marcos e Stael em relação às dificuldades para atender às dúvidas dos alunos e Ingrid quando fala da necessidade de atenção para a escolha e seleção do material didático. Retomando os dados de Soraia e Fernanda, podemos entrever que elas enfrentaram situações inesperadas que afetaram o desenvolvimento da proposta de ensino planejada. Ao observarem que os estudantes tinham dificuldades para manusear e utilizar os instrumentos, como régua, compasso e transferidor, os licenciandos tiveram que fazer ajustes para superar tais desafios e progredir nas tarefas de ensino. Esses inesperados trouxeram reflexos para o dimensionamento do tempo e impactaram as expectativas sobre a evolução do trabalho pedagógico. Essas experiências trazem novos conhecimentos da docência a partir da tentativa de solucionar problemas, conforme indica Moura (2000).

O extrato de Elen também sinaliza que, ao tentar explicar o conceito de produtos notáveis, precisava de maior domínio do conteúdo para abordar com mais clareza para os alunos. Indica que foi tomada pela sensação de insegurança, o que talvez tenha colaborado para não alcançar plenamente o objetivo proposto da ação. Todas essas compreensões advindas da relação com o coletivo dos estudantes revelam uma nova ou outra qualidade para os conhecimentos docentes dos licenciandos (LOPES, 2009). Nessa perspectiva, os inesperados que surgem no contexto das situações reais das experiências didáticas do estágio supervisionado, conforme descrito pelos licenciandos, revelam-se como momentos promissores que desencadeiam aprendizagens sobre o trabalho educativo. Com base em Caraça (1951 p. 112), podemos inferir, então, que é no "[...] aparecimento do inesperado [que] reside um dos motivos principais do progresso no conhecimento da realidade". Esses inesperados possibilitam aos licenciandos situações que os levam a um exame mais cuidadoso das condições iniciais das suas propostas didáticas. Aproveitamos esses momentos para ampliar discussões e reflexões acerca das mudanças necessárias para adequar as propostas e aprender com esses inesperados. Desse modo, eles desenvolvem novas elaborações, especialmente por meio da atividade de avaliação das ações, que também iremos expor no episódio 3. 
Episódio 3 - Avaliação das oficinas e aprendizagem docente

Kauã (2015) - Aprendi que existe uma diferença muito grande entre saber o conteúdo e saber ensinar ele. Na oficina fiquei frustrado com o resultado pois não atingi meus objetivos e não soube lidar com as adversidades em sala de aula quanto as dúvidas dos alunos.

Marcos (2016) - Considero que a aula foi proveitosa e constatei que várias coisas que discutimos ao longo do curso de estágio se confirmaram na prática. Trazer os alunos para um ambiente diferente do habitual (LEM), montar atividades com materiais concretos auxiliam o professor e tornam a aula mais interessante e motivadora para os alunos. Afirmo isso com base nas observações realizadas na escola em comparação com a oficina, pois notei, de forma geral, um maior envolvimento dos alunos. Em especial dois destes me chamaram a atenção, já que participaram de forma ativa na resolução dos problemas no Lem, enquanto nas aulas na escola ficavam sempre dispersos utilizando seus celulares.

Elen (2017) - As mudanças que eu faria era realizar essa sequência em três aulas de uma hora cada, para que os alunos consigam consolidar melhor os conceitos, evitar que eles fiquem cansados e para poder avaliar melhor o que eles conseguiram compreender com as tarefas (feedback). Também teria em conta as contribuições que o professor de estágio sugeriu durante o desenvolvimento da oficina, como por exemplo, na hora de calcular a área de uma figura, mostrar para os alunos que existem diversas formas para poder chegar ao mesmo resultado ou começar explicando cada um dos produtos notáveis com valores numéricos e depois passar na parte algébrica. Enfim, aprendi sobre a importância da planificação prévia de um conteúdo, a distribuição do tempo na oficina e que os alunos gostam de participar em sala de aula, só que isso acontece quando o tema é abordado de uma forma mais dinâmica, interativa, clara e desafiadora.

Fernanda (2017) - Algo que mudaria na oficina seria uma aula prévia só com o uso dos instrumentos, deixar os alunos desenvolverem segurança em usá-los, talvez as construções dos polígonos teriam sido mais fáceis. Uma aula de 120 minutos não é suficiente para ensinar os alunos a usarem algo e saber como manuseá-los perfeitamente. $O$ auxílio de nossos colegas e professores foi fundamental para que todos os alunos tivessem suas dúvidas sanadas e suas construções finalizadas. A importância de um planejamento só é vista quando estamos no meio do fogo cruzado e ainda sim temos que deixar espaço aberto para os imprevistos.

Ingrid (2018) - Como citei anteriormente, as maiores dificuldades foram sentidas, especialmente por não ter um plano de aula desenvolvido e bem trabalhado, e ter confiado no material, sem ter conferido com antecedência se todos os tabuleiros estavam corretos.

Fonte: Dados da pesquisa.

Verificamos que os enunciados do episódio 3 realçam que as experiências didáticas objetivadas por meio das oficinas pedagógicas foram proveitosas para os licenciandos em termos de aprendizagens. Eles notaram que a realidade da sala de aula é sempre mais complexa e rica de situações do que podemos imaginar e contemplar em nossos planejamentos. Embora essa etapa seja essencial, como evidenciado pelas acadêmicas Elen, Fernanda e Ingrid, a idealização do processo de ensino de conceitos matemáticos encontra validade a partir do encontro com o outro, ou seja, na concreticidade da atividade pedagógica. Os licenciandos chegam à etapa da avaliação com uma qualidade nova de conhecimentos docentes que subsidiam novas proposições, como situadas por Elen e Fernanda, que enunciam a necessidade da reconfiguração da distribuição das tarefas e do tempo.

Os diferentes extratos nos indicam que "não basta olhar para as coisas da vida; é preciso sentir e pensar sobre elas para conhecê-las" (LANNER de MOURA, 1998, p. 6). Nessa dinâmica, reconhecemos superações e aprendizagens que colaboram para a constituição do conhecimento docente e do ser professor. Entendemos que os vários dados apontam que as atividades formativas proporcionadas pelo estágio curricular supervisionado estimulam a emergência de conflitos e descobertas. Nesse processo ocorrem significações diversas. 
A significação é aquilo que num objeto ou fenômeno se descobre objetivamente num sistema de ligações, de interações e de relações objetivas. A significação é refletida e fixada na linguagem, o que lhe confere a sua estabilidade. Sob a forma de significações linguísticas, constitui o conteúdo da consciência social: entrado no conteúdo da consciência social, torna-se assim a consciência real dos indivíduos, objetivando em si o sentido subjetivo que o refletido tem para eles (LEONTIEV, 1978, p. 100).

Desse modo, compreendemos que os vários enunciados da pesquisa expressam um conjunto de significações tecidas na coletividade do estágio curricular supervisionado e indicam movimentos de aprendizagem de conhecimentos da docência na imbricada relação entre planejamento, desenvolvimento e avaliação das ações de ensino, concretizadas na forma de oficinas pedagógicas de matemática.

\section{CONSIDERAÇÕES FINAIS}

Neste artigo, assumimos que a aprendizagem é um processo que se inicia no terreno social, sendo a interação entre sujeitos um aspecto essencial e basilar para estimular e desencadear o desenvolvimento humano. No caso da aprendizagem da docência, indicamos que esse processo está em estreito diálogo com o conceito de atividade pedagógica. Partimos da compreensão de que esse conceito expressa uma unidade dialética que permite analisar dimensões formativas do trabalho do professor e do estudante, quando estabelecem relações com o conhecimento. Focalizamos, em nossas reflexões, as relações específicas com a apropriação de conhecimentos sobre o ensino de matemática que marcam o trabalho docente. Nesse sentido, privilegiamos episódios com cenas constituídas por enunciados que avaliamos como reveladores do movimento de alteração do pensamento dos licenciandos e que apresentam indícios de aprendizagens de conhecimentos docentes. Entendemos que essas cenas retratam ações formativas que podem ser relacionadas à noção de atividade de Leontiev (1978).

Os licenciandos, ao formularem seus enunciados com base na experiência da atividade pedagógica, mostram que agregaram conhecimentos durante as várias etapas, desde o planejamento até a avaliação das oficinas pedagógicas. Por meio desses enunciados, sinalizam que essas ações ofereceram condições para os licenciandos alterarem e/ou modificarem suas compreensões em termos de conhecimentos matemáticos e pedagógicos, que constituem a atividade principal do professor, que é a atividade de ensino.

Nessa perspectiva, percebemos que a unidade teoria e prática se manifesta na dinamicidade das ações de ensino e na relação com o outro. Defendemos, assim, que o estágio supervisionado na formação inicial do professor de Matemática constitui um momento privilegiado para ações colaborativas e coletivas de elaboração de situações de ensino que revelam o professor como artesão do seu trabalho. Trabalho com autoria, coautoria, criação e possibilidade de recriação, a partir da atitude crítica da avaliação do processo desenvolvido na escola e no estágio e, no caso desta pesquisa, também na ação de ensino realizada no Laboratório de Ensino de Matemática. Conceber o processo de formação docente nesse horizonte de coletividade se alinha a um certo modo de organização que permita aos sujeitos "[...] não somente a vivência da atividade de ensino, 
mas a reflexão e a tomada de consciência das suas ações, possibilitando a superação da alienação do sujeito humano diante de si mesmo" (LOPES et al., 2016, p. 18).

Assim, concluímos este artigo apostando na defesa de que as ações formativas no estágio supervisionado requerem modos de organização coletiva. Para isso, é preciso entender que a "[...] organização do ensino leva à organização do trabalho coletivo, da mesma forma em que a organização do trabalho coletivo leva à organização do ensino" (LOPES et al., 2016, p. 26).

Artigo recebido em: 31/01/2020

Aprovado para publicação em: 17/05/2020

\section{SUPERVISED EDUCATIONAL CURRICULUM STAGE AND MATHEMATICS TEACHING LABORATORY: TRAINING ACTIONS SHARED WITH BASIC EDUCATIONAL SCHOOLS}

ABSTRACT: This article explores the learning process of Math graduated teachers in the supervised stage. It is a qualitative research that aims to understand the movement of formative action on graduates when they carry out pedagogical workshops with students of Elementary School, in a teaching mathematics laboratory. Based on the assumptions of the Historical-Cultural approach and the Activity Theory, we analyze formative episodes recorded in reports written between 2015 and 2018, which explain the reflections, challenges and possibilities of teaching elaborated by academics. The analyses indicate that the moments of planning, development and evaluation of the workshops, from a collective perspective; contribute to the constitution of a new way of thinking presented by the graduated teachers on the pedagogical activity.

KEYWORDS: Supervised stage. Mathematics. Teaching Laboratory. Teaching learning.

\section{PASANTÍA CURRRICULAR SUPERVISADA Y LABORATORIO DE MATEMÁTICA: ACCIONES FORMATIVAS COMPARTIDAS CON ESCUELAS DE EDUCACIÓN BÁSICA}

RESUMEN: El artículo explora la temática del aprendizaje docente de estudiantes del profesorado de matemática en las pasantías supervisadas. Se trata de una investigación cualitativa que pretende comprender el movimiento de la acción formativa de los futuros docentes cuando realizan oficinas pedagógicas con estudiantes de educación fundamental, en un laboratório de matemática. En base a los presupuestos del enfoque Histórico-Cultural y de la Teoria de la Actividad, analisamos episódios formativos registrados en relatórios escritos entre 2015 y 2018, que explicitan reflexiones, desafios y posibilidades de enseñanzas elaboradas por académicos. Los análisis indican que los momentos de planificación, desarrollo y evaluación de las oficinas, en una perspectiva colectiva, contribuyen a la constitución de una nueva calidad de pensamiento de los docentes en formación sobre la actividad pedagógica.

PALABRAS CLAVE: Pasantía supervisada. Matemática. Laboratório de matemática. Aprendizaje docente. 
CÔCO, D.; SILVA, S. A. F. da

\section{REFERÊNCIAS}

BAKHTIN, M. Estética da criação verbal. São Paulo: Martins Fontes, 2003.

BAKHTIN, M. Problemas da poética de Dostoiévski. Rio de Janeiro: Forense Universitária, 2005.

CARAÇA, B. Conceitos fundamentais da Matemática. Lisboa:Tipografia Matemática, 1951.

DIAS, M. da S.; SOUZA, N. M. M. de. A atividade de formação do professor na licenciatura e na docência. In: MOURA, M. O. de (org.). Educação escolar e pesquisa na teoria Histórico-Cultural. São Paulo: Edições Loyola, 2017. p. 183-210.

LEONTIEV, A. O desenvolvimento do psiquismo. Tradução de Manoel Dias Duarte. Lisboa: Livros Horizontes, 1978.

LOPES, A. R. L. V. Aprendizagem da docência em matemática: o clube de Matemática como espaço de formação inicial de professores. Passo Fundo: Editora Universidade de Passo Fundo, 2009.

LOPES, A. R. L. V. et al. Trabalho coletivo e organização do ensino de matemática: princípios e práticas. Revista ZETETIKÉ, v. 24, n. 45, jan./abr. 2016.

LANNER de MOURA, A. R. de. Fazendo-me professora. Cadernos Cedes, v. 19, n. 45, 1998.

MORETTI, V. D.; MOURA, M. O. de. Professores de matemática em atividade de ensino: contribuições da perspectiva histórico-cultural para a formação docente. Ciência e Educação (Bauru), v.17, n. 2, p. 435-450, 2011.

MOURA, M. O. de; SFORNI, M. S. de F.; LOPES, A. R. L. V. A objetivação do ensino e o desenvolvimento do modo geral da aprendizagem da atividade pedagógica. In: MOURA, M. O. de (org.). Educação escolar e pesquisa na teoria Histórico-Cultural. São Paulo: Edições Loyola, 2017. p. 71-100.

MOURA, M. O. de. (coord.). O estágio na formação compartilhada: retratos de uma experiência. São Paulo: Feusp, 1999.

MOURA, M. O. de. O educador matemático na coletividade de formação: uma experiência com a escola pública. 2000. Tese (Livre docência) - Faculdade de Educação, Universidade de São Paulo, São Paulo, 2000.

RODRIGUES, P. A. M. Entre experiências de estágio supervisionado e modelos para formação de docentes: reconhecendo o lugar da escola e das parcerias na preparação dos professores. Revista Teias, v. 14, n. 36, p. 200-217, 2014. 


\section{SILVA, M. M. da. A apropriação dos aspectos constituintes da atividade pedagógica por professores de matemática em formação inicial. 2018. Tese. (Doutorado em Educação, em Ciências e Matemática) - Universidade Federal de Goiás, Goiânia, 2018.}

SILVA, M.; CEDRO, W. L. O planejamento compartilhado das ações pedagógicas: a aprendizagem da docência do professor de Matemática. Anais. 37a Reunião Nacional da ANPED, 2015.

DıLZA Côco: Doutora em Educação pela Universidade Federal do Espírito Santo (Ufes). Licenciada em Pedagogia pela Ufes. Atua na licenciatura em matemática do Ifes, no Programas de Pós-Graduação em Educação, em Ciências e Matemática (Educimat) e no Programa de Pós-Graduação em ensino de Humanidades, ambos do lfes. Vice-líder do Grupo de Pesquisa em Prática Pedagógica de Matemática (Grupem) e participa do Grupo de Estudos e Pesquisas em Atividade Pedagógica (GEPAPe).

Orcid: https://orcid.org/0000-0001-8371-8517

E-mail: dilzacoco@gmail.com

Sandra Aparecida Fraga da Silva: Possui estágio pós-doutoral em Educação matemática $e$ ensino de física pela UFSM. Doutora e mestre em Educação pela Ufes. Licenciada em Matemática pela Ufes. Atua na licenciatura e no Programa de Pós-graduação em Educação em Ciências e Matemática no Ifes. Líder do Grupo de Pesquisa em Prática Pedagógica de Matemática (Grupem) e participa do Grupo de Estudos e Pesquisas em Atividade Pedagógica (GEPAPe). Atualmente é bolsista Pesquisador Capixaba Fapes, EDITAL FAPES $N^{\circ} 18 / 2018$.

Orcid: https://orcid.org/0000-0002-0902-627X

E-mail: sandrafraga7@smail.com

Este periódico utiliza a licença Creative Commons Attribution 3.0, para periódicos de acesso aberto (Open Archives Iniciative - OAI). 